\title{
Evaluation of Line Power Losses under Variable Power Supplied by Wind Generation and PV Attached at Different Bus-bars
}

\author{
Mustafa Jameel ${ }^{\dagger}$, Ali Salam Kadhim \\ 'Department of Electrical and Electronics Engineering, University of Thi-Qar, Thi-Qar, Iraq, Email. \\ * Department of Electrical and Electronics Engineering, University of Thi-Qar, Thi-Qar, Iraq, ali-al- \\ khayyat@utq.edu.iq.
}

\begin{abstract}
The aim of this paper is to solve the load flow for Power System Connection (IEEE 6 Bus System), and find the power losses in the transmission lines and the total power losses for 10 MVA base power rating and $33 \mathrm{KV}$ rated voltage. This can be achieved with the aids of simulation by using a software programme called PSAT, which is compatible with MATLAB. In addition, to improve the efficiency of the system a $2 \mathrm{MW}$ wind turbine has to be installed on the system, but due to the fact that the wind turbine has changeable output power and this leads to variation in the voltages and currents in the transmission system. Therefore, we will examine the effect of the $2 \mathrm{MW}$ wind turbine at different busbars and find out where is the optimal location for the turbine, which results in low system losses and optimum voltage. The next section is to apply a PV generator with variable output on different busbars and find the best position that we can obtain less power losses and optimum voltage regulation. The final section is to apply $0.5 \mathrm{PV}$ generators at different buses at the same time and compare the result with the case obtained from applying 2 MW PV generators.
\end{abstract}

Keywords: Load flow, Power losses, PSAT, Wind turbine, Optimum voltage.

\section{Introduction}

Active and Reactive power in all three phase AC power system are flowing from the generation station where the AC power is generated to the load where it is consumed via many buses and transmission lines branches. Studying power flow from generation station to the load called load flow studies or power flow studies, such type of studies are in the category of the steady state analysis for the operation condition of a power system, and their aim is to calculate the

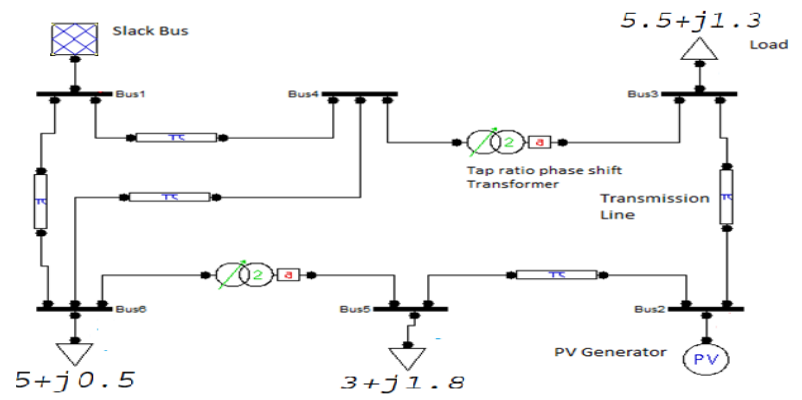

voltages, phase angle, real and reactive power flows through the system for a specific load condition. Moreover, in these studies we make an assumption either for the value of the bus voltages or for the power, which has been supplied to the bus. The purpose of the power flow analysis is to provide the consumer with the power that needs in real time and with suitable limits for the voltages and frequency. In addition, to anticipate ahead and take into account for any situation that could happen in the system. Such as, if one of the transmission lines is to be taken off for the purpose of maintenance, are the other lines in the system can manage the required load without override their rated values.

Fig.1 Power System Connection (IEEE 6 Bus System)

The bus in the power system is accompanying with four different quantities named as voltage magnitude, voltage phase, real or active power and reactive power. In the procedure of solution the load flow studies, two of those quantities are 
known and the rest should be found. According to those four quantities, the buses in the power system are classified into the following types:

1. Slack bus: Also, called swing bus and it acts as the reference generator for the power system and its voltage magnitude is (1 per unit) and the phase of the voltage is assumed to be zero $\angle 0$. In the slack bus, the active power $\mathrm{P}$ and reactive power $\mathrm{Q}$ generated is unknown and can be found through the load flow solution.

2. Load bus: Also, called P \& Q bus, therefore active and reactive power are known, and the voltage magnitude and phase have to be found from the load flow solution. In this bus, no generator is connected to it.

3. Generator bus: Also, called voltage controlled bus and in this bus the magnitude of the voltages is kept constant and this can be achieved by adjusting the field current of the generator. The real power generation for each generator in this bus is assigned. In this bus the reactive power and the phase of the voltage is unknown.

Many methods can be used to solve the load flow problems such as Gauss-Seidal method and Newton-Raphson (NR) methods, which are based on the iterative technique. Moreover, the programme PSAT uses Newton-Raphson technique to solve problems of load flow in large power network $[1,2,3]$.

The Newton-Raphson method as mentioned in many references is the most computationally efficient and common way used for calculation of load flow. This is because of its several advantages. The convergence characteristics for example of NR are not affected by the choice of a slack bus, while this selection has noticeable effects in Gauss-Siedal. These effects can basically result in poor convergence. In addition, NR approach is very suitable for the large networks because the requirement for the computer storage is reasonable and increase linearly with the problem size. Furthermore, The NR method has a great flexibility, so it allows for a very wide range of requirements, such as, onload-tap changing and phase-shift devices, remote voltage control and functional loads, to be included efficiently. Thus, NR method is crucial for many novel developed techniques, which are required for obtaining the premium operation of a power system, system-state evaluation, analysis accuracy, modeling of linear network and the analysis of transient-stability[4].

\section{Voltage Regulation}

Voltage regulation of the transmission line is a measure of change in the magnitude of the voltage between the sending and receiving end. There are two different types of voltage regulation and this difference depends on the reference voltage:

1. Regulation down: this is the change in the terminal voltage when the full load current for any given power factor is applied, and it is expressed as a fraction of no-load terminal voltage. This kind of regulation is normally used in the transformer.

Regulation voltage $=\frac{|V n l|-|V l|}{|V n l|}$

2. Regulation up: it is the change in the terminal voltage in the case when the full load current for a given load factor is removed. This kind of voltage regulation is used in alternator and power system because the user end voltage (receive) is assured by the provider of power supply. Thus, this one will be used in this coursework.

$$
\text { Regulation voltage }=\frac{|V n l|-|V l|}{|V l|}
$$

Voltage regulation is an important subject in electrical distribution engineering. It is the utilities' responsibility to keep the customer voltage within specified tolerances. The performance of a distribution system and quality of the service provided are not only measured in terms of frequency of interruption but in the maintenance of satisfactory voltage levels at the customers' locations. According to Gonen [3], a high steady-state voltage can reduce the life of devices. On the other hand, a low steady-state 
voltage leads to problem with the apparatus, such as overheating due to harmonics. However, most equipment and appliances operate satisfactorily over some 'reasonable' range of voltages; hence, certain tolerances are allowable at the customer's end. Thus, it is common practice among utilities to stay within preferred voltage levels and ranges of variations for satisfactory operation of apparatus as set by various standards such as ANSI (American National Standard Institution). In this simulation, once a load flow solution is obtained, the voltage regulation of any feeder can be calculated as follows:

$$
\text { Voltage Regulation }=\frac{|V s|-|V r| \times 100 \%}{|V r|}
$$

Where $V s$ is sending-end voltage and $V r$ is receiving-end voltage. In distribution systems, this regulation may be typically improved by using one or more of the following techniques:

(a) Increasing primary voltage.

(b) Activating voltage regulating equipment at the substations bus such as capacitors or LTCs.

(c) Balancing of loads on primary feeders.

(d) Increased size of feeder conductor.

(e) Transferring loads to new feeders.

(f) Installing new substations and primary feeders.

(g) Installing shunt capacitors or SVCs on primary feeders.

The most economical way of improving voltage profiles along a feeder, and thus voltage regulation and overall system performance, is by using shunt capacitors [5,6,7]

\section{Basic Algorithm of Solving Load Flow by Newton_Raphson}

Let us consider a given power system which contains an n-node. Then for Kth busbar, which links node $\mathrm{k}$ to node $\mathrm{j}$ by an admittance $\mathrm{Ykj}$ and the number of links decided by number of node ,

$$
P_{k}+j Q_{k}=V_{k} \times I_{k}^{*}=V_{k} \sum_{j=1}^{n-1}\left(Y_{k j} V_{j}\right)^{*}
$$

Let where it start from 1 till n-1.

$$
V_{k}=a_{k}+j b_{k} \text { and } Y_{k j}=G_{k j}+j B_{k j}
$$

Then,

$$
\begin{aligned}
P_{k}+j Q_{k}= & \left(a_{k}\right. \\
& \left.+j b_{k}\right) \sum_{j=1}^{n-1}\left[\left(G_{k j}+j B_{k j}\right)\right. \\
& \left.\times\left(a_{j}+j b_{j}\right)\right]^{*}
\end{aligned}
$$

From which,

$$
\begin{aligned}
P_{k}= & \sum_{j=1}^{n-1}\left[a_{k}\left(a_{k} G_{k j}-b_{j} B_{k j}\right)\right. \\
& \left.+b_{k}\left(a_{j} B_{k j}+b_{j} G_{k j}\right)\right] \\
Q_{k}= & \sum_{j=1}^{n-1}\left[b_{k}\left(a_{j} G_{k j}-b_{j} B_{k j}\right)\right. \\
& \left.-a_{k}\left(a_{j} B_{k j}+b_{j} G_{k j}\right)\right]
\end{aligned}
$$

Thus, for each node there are two non-linear simultaneous equations. Because the slack bus is entirely assigned, we consider the number of node as $\mathrm{n}-1$ in the summation of the above equations. Now the procedure for solving the two non-linear simultaneous equations for active and reactive power $[6,7]$.

Equation

$P_{k}=\sum_{j=1}^{n-1}\left[a_{k}\left(a_{k} G_{k j}-b_{j} B_{k j}\right)+b_{k}\left(a_{j} B_{k j}+\right.\right.$ $\left.\left.b_{j} G_{k j}\right)\right](6)$

is defined for the simplicity as:

$$
\Delta P_{k}=\frac{\partial P_{k}}{\partial a_{1}} \Delta a_{1}+\frac{\partial P_{k}}{\partial a_{2}} \Delta a_{2}+\cdots \frac{\partial P_{k}}{\partial a_{n-1}} \Delta a_{n-1}
$$

Where changes in $\mathrm{P}$ is related to changes in a and $\mathrm{b}$ as they are explained in equation $P^{k}$ and $Q^{k}$.

By the same way, the equation $\Delta P$ and $\Delta b$ and the equation $\Delta Q$ in terms of $\Delta a$ and $\Delta b$.

By Jacobian matrix, we can express these two equations: \begin{tabular}{|l|l|lllll|}
\hline$\Delta P_{1}$ & $\frac{\partial P_{1}}{\partial a_{1}}$ & $\cdots$ & $\frac{\partial P_{1}}{\partial a_{n-1}}$ & $\frac{\partial P_{1}}{\partial b_{1}}$ & $\cdots$ & $\frac{\partial P_{1}}{\partial b_{n-1}}$ \\
& & $\cdots$ & & & &
\end{tabular} \mid $\begin{aligned} & \Delta a_{1} \\
& \end{aligned}$ 


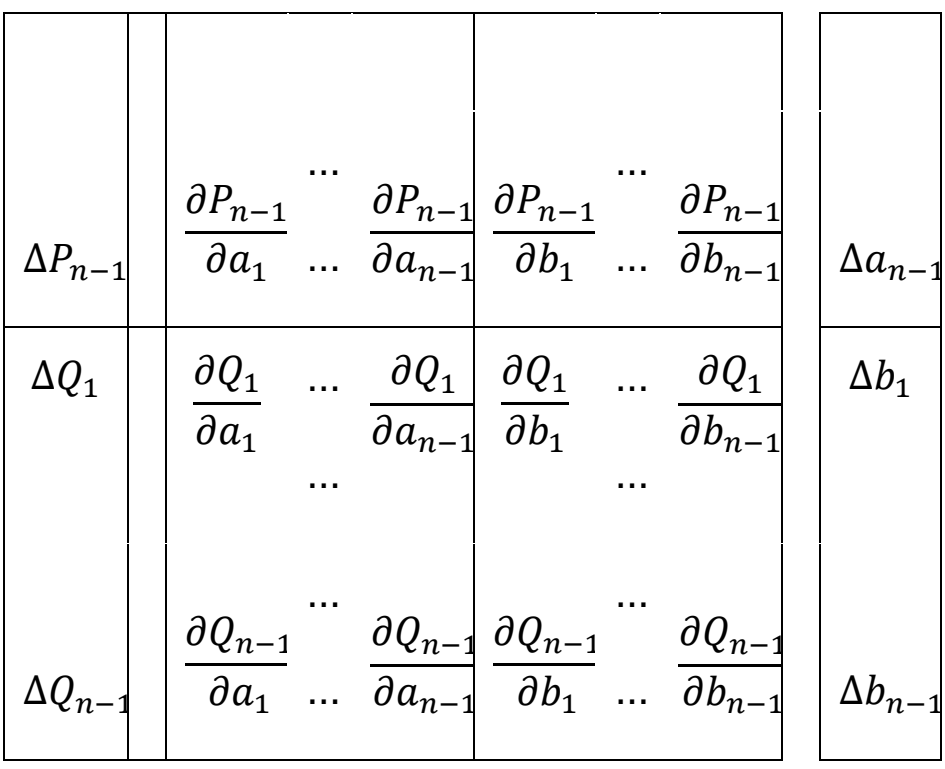

For the sake of simplicity, we will use the notation JA, JB, JC and JD to express the Jacobian matrix:

\begin{tabular}{|l|l|}
\hline$J_{A}$ & $J_{B}$ \\
\hline$J_{C}$ & $J_{D}$ \\
\hline
\end{tabular}

The elements of the above matrix can be calculated for the values $\mathrm{P}, \mathrm{Q}$, and $\mathrm{V}$ at each iteration as explained below:

For the element $J_{A}$ and from equation $P_{k}$ :

$\frac{\partial P_{k}}{\partial a_{k}}=a_{k} G_{k k}-b_{k} B_{k k}+c_{k}$

Off-diagonal elements, where $k \neq j$, are given by:

For $J_{B}$,

$$
\frac{\partial P_{k}}{\partial a_{j}}=a_{k} G_{k j}-b_{k} B_{k j}
$$

$$
\frac{\partial P_{k}}{\partial b_{k}}=a_{k} B_{k k}+b_{k} G_{k k}+d_{k}
$$

And

$$
\frac{\partial P_{k}}{\partial b_{j}}=a_{k} B_{k j}+b_{k} G_{k j}(k \neq j)
$$

For $J_{C}$,

$$
\frac{\partial Q_{k}}{\partial a_{k}}=a_{k} B_{k k}+b_{k} G_{k k}-d_{k}
$$

For $J_{D}$

$$
\frac{\partial Q_{k}}{\partial a_{j}}=a_{k} B_{k j}+b_{k} G_{k j}(k \neq j)
$$

And

$$
\frac{\partial Q_{k}}{\partial b_{k}}=-a_{k} G_{k k}+b_{k k} B_{k k}+c_{k}
$$

$$
\frac{\partial Q_{k}}{\partial b_{j}}=-a_{k} G_{k j}+b_{k} B_{k j}(k \neq j)
$$

The changes are then calculated: $\triangle P k^{p}=P k-$ $P_{k}^{p}$ and $\Delta Q k^{p}=Q-Q_{k}$,

Where $\mathrm{p}$ is the number of iteration.Then, the node currents are calculated.

$$
I_{k=}^{p}\left(\frac{p_{k}^{p}+J Q_{k}^{p}}{V^{p}}\right)=C_{k}^{p}+J d_{k}^{p}
$$

The elements of the Jacobian matrix are then formed.

$$
\left[\begin{array}{l}
\Delta a \\
\Delta b
\end{array}\right]=\left[\begin{array}{ll}
J A & J B \\
J C & J D
\end{array}\right]^{-1}\left[\begin{array}{l}
\Delta P \\
\Delta Q
\end{array}\right]
$$

This is the procedure of Newton-Raphson technique for finding the load flow solution. It is very efficient method for load flow solution in large power system. However, there are some difficulties in the inversion of Jacobian matrix [8-16].

\section{PSAT Simulation}

\section{Section 1:}

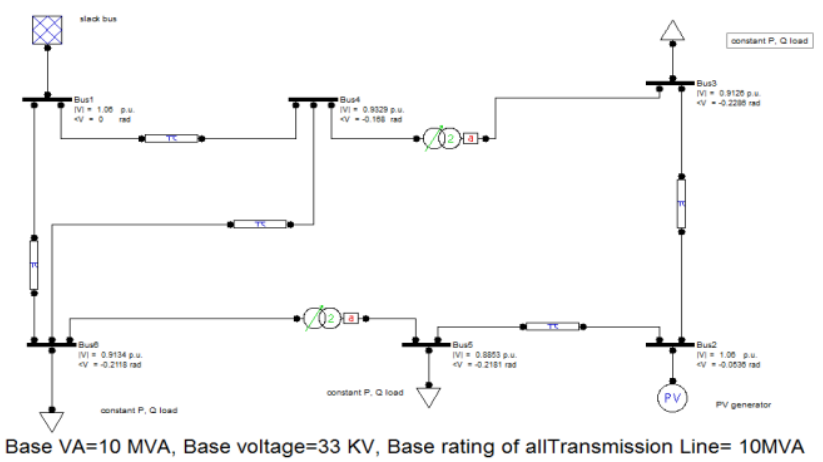

Solve the system below with PSAT and find the power losses in transmission lines and the total system losses.

Fig.2 connection diagram of the 6 bus system 
The load flow results shown in appendix table.1, table. 2 and table.3.

\section{Result of Section 1:}

With the aid of PSAT, we can obtain td he result for the load flow of the 6 bus system. We obtained from the load flow analysis for this system, the voltages magnitude and the phases angle which are corresponding to each bus of the system with $2 \mathrm{MW}$ ( $0.2 \mathrm{p} . \mathrm{u}$ ) PV generator, two phase shift transformer and three load buses. Moreover, we could also find out the losses throughout transmission lines and the total losses in the whole system as mentioned in both tables 2 and 3. Since the purpose of the shift transformer is to adjust the load angle or phase angle between the receiving and transmitting terminals of the transmission lines. The load angle and the reactive power flow through transmission line were controlled using the shift transformer. This was used in order to reduce the losses and obtain a stable voltage. Based on the obtained results, it can be observed that the active power loss is zero between the buses attached to a phase shift transformer i.e. Bus 4 and 3, and Bus 6 and 5, also only the reactive

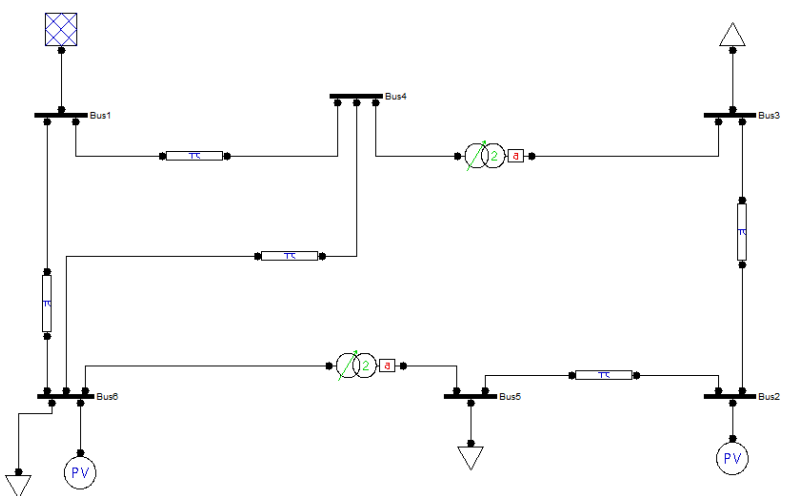

losses obtained between those busses due to the existence of high inductive of the phase-shift transformer only, without resistance. Where, it is clear that the transmission lines without a transformer have significant losses due to the heat $I^{2} \mathrm{R}$ losses. In this part of the simulation, the total generated power and total load power are calculated, and from the difference between them, we can obtain the total system losses, which is $1.0878 \mathrm{MW}$.

\section{Section 2:}

\section{Part 1: Applying 2 MW PV Generator at Different Buses}

Fig.3 Connection Diagram of the 6 Bus systems with extra 2 MW PV generator to different buses

The Total losses of the system and voltage limits of the system when additional 2 MW PV generators added to the system at different locations is shown in the appendix table.4.

\section{Result of Section 2 Part 1:}

It is known that the transfer of the real power depends on the phase angle between the sending and receiving end, while the reactive power depends on the levels of the voltage. We can observe that by connecting additional PV generator to the system, the real power losses has been reduced and an improvement has been made for the voltage regulation due to the reduction in the losses of reactive power. In addition, the bus connected to the generator through a phase-shift transformer have more optimum voltage limits, such as bus 6 and bus 5 since there is no losses in the transmission line between them. Because of the losses in the transmission line between the bus 2 and 3, the voltage limits at bus 3 is not desirable, where it varies considerably, which may lead to some problem. From the analysis of the system with the additional 2 MW PV generator at different buses, we can observe that less total loss can be obtained is when the PV connected to bus 6 as the load at that bus fed directly from the generator and no losses in the transmission line between bus 5 and 6 due to phase-shift transformer, and minimum active power losses in the system which is 0.7581 MVA, and from that we obtained premium voltage regulation, although the average voltage regulation for the system when the PV connected to bus 5 is less compared to bus 6 , but the losses are higher and the voltage of the system when the PV attached to bus 5, vary significantly, this leads to unstable condition for the whole system. Hence, the best location for the PV generator is at bus 6 in terms 
of power losses and voltage regulation, and this regulation for bus 4 is $0.046 \%$ but the total

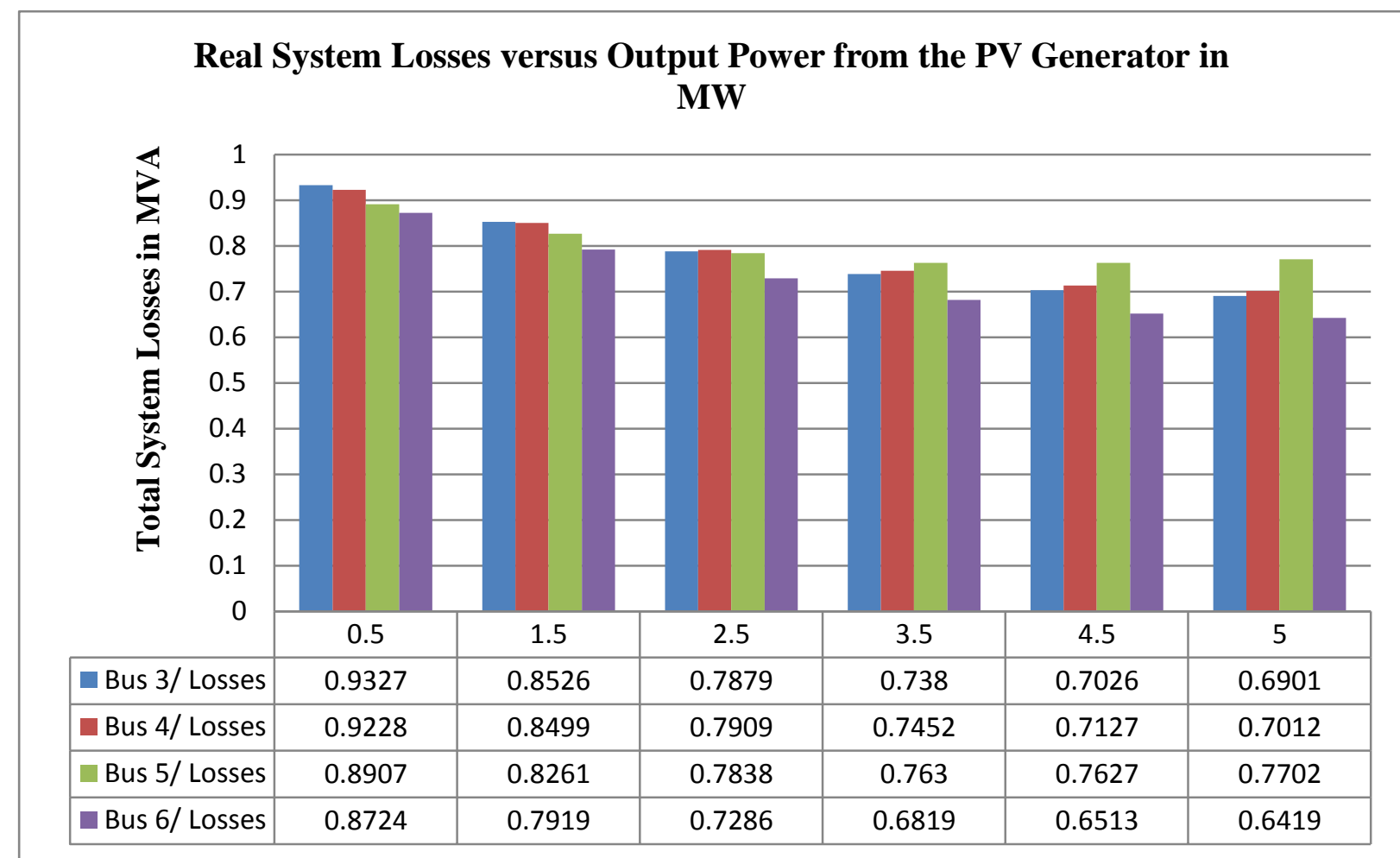

lead to some extent, stable power flow through the system.

\section{Part 2:}

Applying PV generator with variable output of 0.5-5 MW on different busbars in the system. The losses Comparison among Buses shown in the appendix table.5. The data of (0.5-5) MW PV Generator applied at each bus and corresponding voltage regulation is shown in appendix table.6.

The optimal voltage regulation calculated according to the difference between the maximum and minimum voltage regulation. In addition, the total system losses have to be taken into consideration. Hence, the optimum value for the voltage regulation is at bus 6, which is $0.061 \%(6.491 \%-6.430 \%)$, although the voltage system losses are higher than the losses at bus 6 . Moreover, the difference between the voltage regulation at bus 4 and 6 is not big difference. The best location for the PV generator is at bus 6 , but the value of the PV generator should be between 3.5 MW-5 MW, where the voltage regulation for that range of PV approximately stays the same. Below this range of PV generator, the variation of the variation of the bus voltage would be significant, if the optimization is desired.

\section{Total System Losses}

The figure below shows the total system losses against the output power from the PV generator. Where the $\mathrm{X}$-axis represents the corresponding PV generator while the $y$-axis represents the real power losses in MVA.

Fig.4 Active losses against various Output power from the PV Generator. 
Fig.5 Voltage Regulation against various Output Power from PV Generator.

\section{Voltage Regulation versus Output Power from PV Generator}

In order to find out the optimal value for the system voltage regulation, the difference between the maximum voltage regulation and the minimum voltage regulation in the bus need to be calculated.

\section{Result of Section 2 Part 2:}

In this part, we have applied a PV generator with variable output of (0.5-5 MW), on different busbars within the system in order to find out the optimal value and the location of the PV generator in terms of the voltage system regulation and the total system losses. From the analysis of the system in this case, we can notice that as the output power from the additional PV generator increased, the total system losses minimum voltage regulation got from attached 4.5 MW to bus 6 , which is $6.430 \%$. In order to obtain a stable system, the losses should be reduced and the voltage regulation should be minimum. This can be obtained in bus 6 , where it has lower losses and optimum average voltage regulation particularly for value of PV output generator from (3.5-5 MW). Where the voltage regulation approximately stays the same for output PV generator form (3.5-5 MW), which is $6.43 \%$, therefore the

system is in stable condition for this case. By comparing the result obtained from PSAT, we can note that the behavior of system with variable output power from (3.5-5 MW) at bus 6 is similar to the behavior with wind generator installed at bus 6 .

\section{Section 2 Part 3:}

Applying $0.5 \mathrm{MW} \mathrm{PV}$ generator at 4 different locations within the system at the same time.

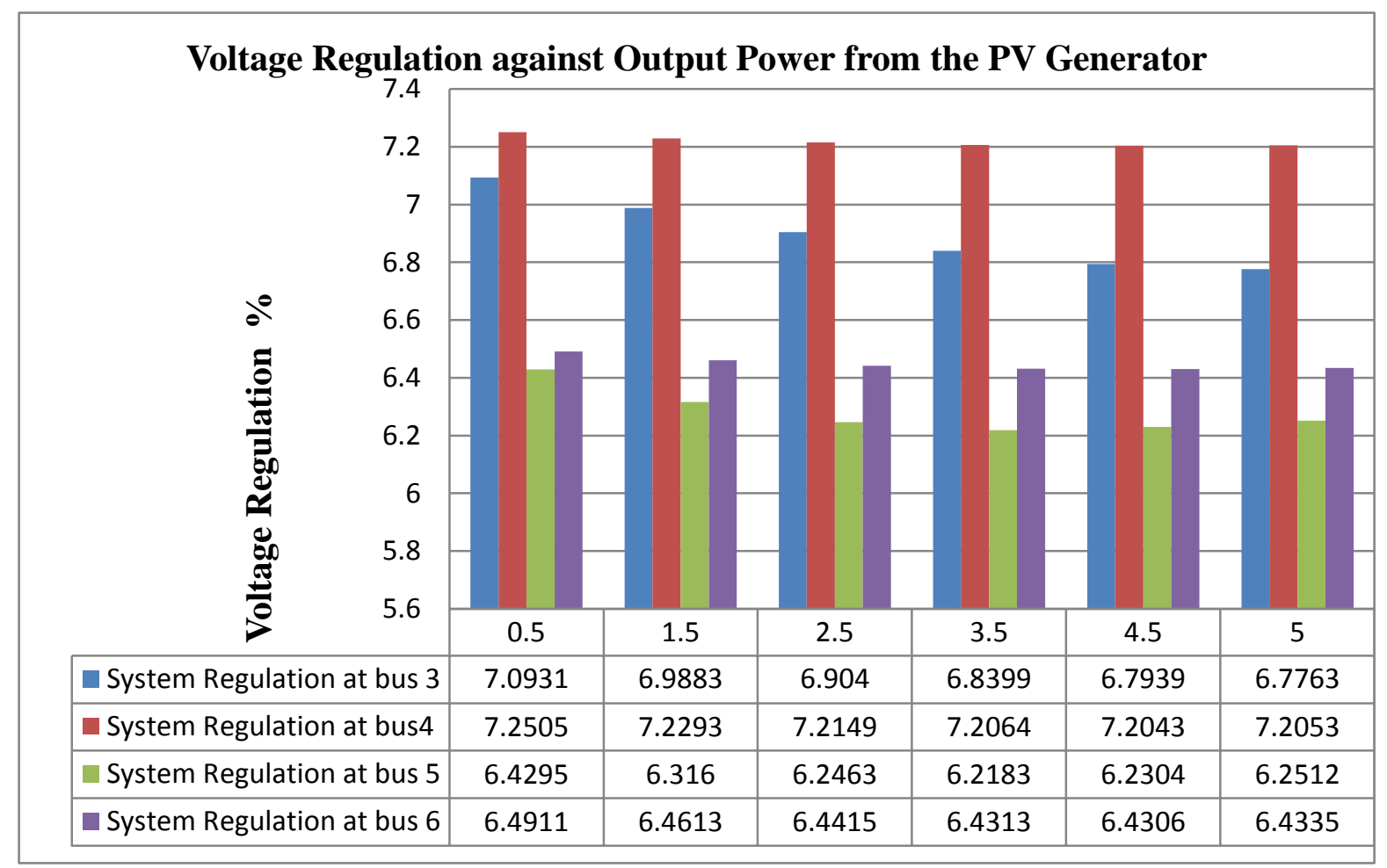

decreased. As far as the losses in the system are concern, bus 6 has less losses (around 0.6419 MVA) compared to the other buses, and this is happened with $5 \mathrm{MW} \mathrm{PV}$ generator and
The total losses of the system and the voltage limits when extra 0.5 MW PV generators added to different buses of the system at the same time are shown in appendix table. 7 and the data of 2 
MW PV generator at bus 6 is shown in appendix table.8.

\section{Result of Section 2 Part 3:}

In this part, 0.5 MW PV generators have been applied at different location all together. From the analysis with the help of PSAT, we noticed that active losses have been improved where it is $\underline{\mathbf{0 . 7 3 4 5}}$ MVA compared with single $2 \mathrm{MW}$ generator at single bus (bus 6) as shown in table (8), where each load will be fed directly from the same bus and thus no losses due to transmission line. Moreover, the voltage limit has been enriched at each bus to its rated value, thus the voltage regulation of the whole system has been enhanced. Comparing this case with $2 \mathrm{MW} \mathrm{PV}$ generator at single bus, we have seen that the active losses and the voltage regulation has been improved only for the specified bus (bus 6) and not for the whole system as happened in this case. However, the voltage regulation at bus 6 is optimum, but the voltage regulations of others are varying considerably, hence the system is not well stable compared to this case. We can conclude that applying generator of $0.5 \mathrm{MW}$ at each bus is better than applying PV generator of $2 \mathrm{MW}$ at single bus.

\section{Conclusions}

In the power system, many components are used for transmission and distribution, such as resistance, capacitance, inductance, and transformer. The resistances in the transmission line cause the major losses in the system. Moreover, according to the power triangle, the load factor can be controlled by the reactive current. One way of improving the power factor and controlling the reactive power in order to stabilize the system voltage is by using some component, such as phase shift transformer and any capacitor bank that offset the effects of inductance and improve the reactive power. In addition, in order to attain a balance power flow in the power system, the voltage magnitude of the bus should be close to its rated value as possible, and the voltage regulation should be as minimum as possible. It was also concluded that in order to obtain less losses in the active power, the PV should be installed in a point that assures less current flow through transmission line. Finally, it was concluded that the position of phase shift transformer should be allocated carefully as it does not has resistive component, thus zero active power losses can be achieved and stabilize system voltage can be obtained.

\section{References}

[1] Arthur, R. and Vittal, V. (2006). Power System Analysis $2^{\text {nd }}$ Edition. India: Dorling Kindersley.

[2] S. D Varwandkar and M. V. Hariharan, "Restructuring the load flow for power systems in deregulated environment, Presented at the 5th International Conference Power and Energy Systems-ICPS, 28-30 October, Kathmandu, Nepal 2013.

[3] Report of the Task Force on Technical Study in regard to Grid Stability, October 2014, New Delhi (available on the net).

[4] D. Shirmohamadi, H.W. Hong and A. Semlyen, "A compensation-based power flow method for weakly meshed distribution and transmission

networks," IEEE Transaction on Power system, vol.3, no.2, pp. 753-762, 1998.

[5] S. Mishra, D. Das and S Paul, "A simple algorithm for distribution system load flow with distributed generation," IEEE conference on Recent Advances and Innovations in Engineering, pp. 1-5, May 2014.

[6] R. Ranjan, B. Venkatesh and D. Das, "Load flow algorithm of radial distribution networks incorporating composite load model," International Journal of Power and Energy Systems, vol. 23, no.1, pp. 71-76, 2003.

[7] U. Eminoglu and M.H. Hocaoglu, "A new power flow method for radial distribution systems including voltage dependent load 
models," Electric Power Systems Research, vol. 76, no. 1-3, pp. 106-114, 2005.

[8] A. Chaturvedi. Load flow analysis and planning of radial distribution systems- A new approach of load modelling, Load forecasting and feeder planning, $\mathrm{PhD}$ Thesis, Multimedia University, pp. 37, July 2005.

[9] S. Singh, and T.Ghose, "Improved radial load flow method," Elect. Power and Energy Syst., vol. 44, pp. 721-727, 2013.

[10] J. H. Teng, "A Direct Approach for Distribution System Load Flow Solutions," IEEE Trans. on Power delivery, vol. 18, no. 3, pp.882-887, July 2003.

[11] V. V. S. N. Murty and A. Kumar, "Optimal placement of DG in radial distribution systems based on new voltage stability index under load growth," Int. J. Electr. POWER ENERGY Syst., vol. 69, pp. 246-256, 2015.

[12] U. Jmail, A. Amin, and A. Mahmood, "A Comparative Study of Control Techniques for Power Loss Minimization in a Distribution Network," in 2018 1st International Conference on Power, Energy and Smart Grid (ICPESG), pp. 1-5, 2018.

[13] P. Mehta, P. Bhatt, and V. Pandya, "Challenges and Solutions for Improvement in Radial Distribution Network: A Review," in International Conference on "Women in Science and Technology: Creating Sustainable Career" ICWSTCSC - 2016, 2016.

[14] S. U. Haq, S. Bhatti, A. Javaid, and Z. Raza, "Electric Power Transmission and Distribution Losses Overview and Minimization in Pakistan,” Int. J. Sci. Eng. Res., vol. 6, pp. 1108-1112, 2015.

[15] D. Wang et al., "Theory and application of distribution electronic power transformer," Electr. Power Syst. Res. J., vol. 77, no. 3, pp. 219-226, Mar. 2007.
[16] M. Kang, P. N. Enjeti, and I. J. Pitel, "Analysis and design of electronic transformers for electric power distribution system," IEEE Trans. Power Electron., vol. 14, no. 6, pp. 11331141, Nov. 1999. 
Appendices

Table.1 Bus data for the IEEE 6 Bus system

\begin{tabular}{|c|c|c|c|c|c|c|c|c|c|}
\hline $\begin{array}{c}\mathrm{Bu} \\
\mathrm{s} \\
\text { No. }\end{array}$ & $\begin{array}{c}\text { Bus } \\
\text { Nam } \\
\text { e }\end{array}$ & $\begin{array}{c}\text { Voltage } \\
\text { (pu) }\end{array}$ & $\begin{array}{l}\text { Phase } \\
\text { Angle } \\
\text { (rad.) }\end{array}$ & $\begin{array}{l}\text { Active } \\
\text { Power } \\
\text { MVA }\end{array}$ & $\begin{array}{c}\text { Reactiv } \\
\text { e Power } \\
\text { MVA }\end{array}$ & $\begin{array}{l}\text { Active } \\
\text { Deman } \\
\text { d MVA }\end{array}$ & $\begin{array}{l}\text { Reactiv } \\
\text { e } \\
\text { Demand } \\
\text { MVA }\end{array}$ & $\begin{array}{c}\text { Voltage } \\
\text { Regulatio } \\
\text { n } \\
\%\end{array}$ & $\begin{array}{c}\text { Average } \\
\text { Regulatio } \\
\mathbf{n} \\
\%\end{array}$ \\
\hline 1 & Bus 1 & 1.06 & 0.00 & $\begin{array}{c}9.587 \\
8\end{array}$ & 5.2645 & 0 & 0 & $\mathbf{0}$ & \multirow{6}{*}{$\underline{10.91}$} \\
\hline 2 & Bus 2 & 1.06 & $\begin{array}{c}- \\
0.053 \\
6\end{array}$ & 5 & 2.0575 & 0 & 0 & $\mathbf{0}$ & \\
\hline 3 & Bus 3 & $\begin{array}{c}0.9126 \\
5\end{array}$ & $\begin{array}{c}- \\
0.228 \\
6\end{array}$ & 0 & 0 & 5.5 & 1.3 & 16.14 & \\
\hline 4 & Bus 4 & $\begin{array}{c}0.9329 \\
6\end{array}$ & $\begin{array}{c}- \\
0.168 \\
0\end{array}$ & 0 & 0 & 0.0 & 0.0 & 13.61 & \\
\hline 5 & Bus 5 & $\begin{array}{c}0.8853 \\
4\end{array}$ & $\begin{array}{c}- \\
0.218 \\
1\end{array}$ & 0 & 0 & 3.0 & 1.8 & 19.72 & \\
\hline 6 & Bus 6 & $\begin{array}{c}0.9134 \\
4\end{array}$ & $\begin{array}{c}- \\
0.211 \\
8\end{array}$ & 0 & 0 & 5.0 & 0.5 & 16.04 & \\
\hline
\end{tabular}

Table.2 Power losses in the transmission lines

\begin{tabular}{|c|c|c|c|c|c|c|}
\hline $\begin{array}{c}\text { From } \\
\text { Bus }\end{array}$ & To Bus & Line & P Flow (pu) & Q Flow (pu) & P Loss (pu) & Q Loss (pu) \\
\hline Bus 1 & Bus 4 & 1 & 0.50991 & 0.29133 & 0.02456 & 0.11357 \\
\hline Bus 1 & Bus 6 & 2 & 0.44887 & 0.23512 & 0.02811 & 0.11837 \\
\hline Bus 5 & Bus 2 & 3 & -0.28295 & -0.09714 & 0.0322 & 0.07307 \\
\hline Bus 3 & Bus 2 & 4 & -0.16205 & -0.00242 & 0.0228 & 0.03311 \\
\hline Bus 6 & Bus 4 & 5 & -0.09629 & -0.01885 & 0.00112 & 0.0047 \\
\hline Bus 4 & Bus 3 & 6 & 0.38795 & 0.15421 & $\underline{0}$ & 0.02663 \\
\hline Bus 6 & Bus 5 & 7 & 0.01705 & 0.0856 & $\underline{0}$ & 0.00274 \\
\hline Bus 4 & Bus 1 & 1 & -0.48536 & -0.17776 & 0.02456 & 0.11357 \\
\hline Bus 6 & Bus 1 & 2 & -0.42076 & -0.11675 & 0.02811 & 0.11837 \\
\hline Bus 2 & Bus 5 & 3 & 0.31515 & 0.17021 & 0.0322 & 0.07307 \\
\hline Bus 2 & Bus 3 & 4 & 0.18485 & 0.03553 & 0.0228 & 0.03311 \\
\hline Bus 4 & Bus 6 & 5 & 0.09741 & 0.02355 & 0.00112 & 0.0047 \\
\hline Bus 3 & Bus 4 & 6 & -0.38795 & -0.12758 & 0 & 0.02663 \\
\hline
\end{tabular}


Table.3 Global summary report

\begin{tabular}{|c|c|c|c|}
\hline Sr No. & Description & Real Power (MVA) & Reactive Power (MVA) \\
\hline 1 & Total Generation & 14.588 & $\mathbf{7 . 3 2 1 9}$ \\
\hline 2 & Total Load & 13.5 & 3.6 \\
\hline 3 & Total System Losses & $\underline{1.0878}$ & $\underline{3.7219}$ \\
\hline
\end{tabular}

Table.4 Total losses of the system and voltage limits of the system when additional 2 MW PV generators added to the system at different locations

\begin{tabular}{|c|c|c|c|c|c|c|c|}
\hline $\begin{array}{c}\text { Additional } \\
\text { PV } \\
\text { Generator } \\
\text { applied on } \\
\text { different } \\
\text { buses }\end{array}$ & Bus Name & Voltage (KV) & $\begin{array}{c}\text { Phase Angle } \\
\text { (rad) }\end{array}$ & $\begin{array}{c}\text { Voltage } \\
\text { regulation } \\
(\%)\end{array}$ & $\begin{array}{c}\text { Real } \\
\text { Power } \\
\text { (MVA) }\end{array}$ & $\begin{array}{c}\text { Reactive } \\
\text { Power } \\
\text { (MVA) }\end{array}$ & $\begin{array}{l}\text { Average } \\
\text { Regulation }\end{array}$ \\
\hline \multirow{6}{*}{$\begin{array}{c}\text { 2MW @ } \\
\text { Bus } 3\end{array}$} & Bus -1 & 34.98 & 0 & 0 & \multirow{6}{*}{0.8183} & \multirow{6}{*}{2.5003} & \multirow{6}{*}{$6.94 \%$} \\
\hline & Bus -2 & 34.98 & 0.02737 & 0 & & & \\
\hline & Bus -3 & 33 & -0.14664 & 6 & & & \\
\hline & Bus -4 & 32.89506 & -0.11836 & 6.338155334 & & & \\
\hline & Bus -5 & 29.83827 & -0.16563 & 17.2319977 & & & \\
\hline & Bus -6 & 31.20645 & -0.16966 & 12.09221171 & & & \\
\hline \multirow{7}{*}{$\begin{array}{c}\text { 2MW@ } \\
\text { Bus } 4\end{array}$} & Bus -1 & 34.98 & 0 & 0 & \multirow{6}{*}{0.81878} & \multirow{6}{*}{2.6786} & \multirow{6}{*}{$7.221 \%$} \\
\hline & Bus -2 & 34.98 & 0.01068 & 0 & & & \\
\hline & Bus -3 & 32.18094 & -0.17181 & 8.697881417 & & & \\
\hline & Bus -4 & 33 & -0.11727 & 6 & & & \\
\hline & Bus -5 & 29.95443 & -0.17212 & 16.77738485 & & & \\
\hline & Bus -6 & 31.27344 & -0.17188 & 11.85210198 & & & \\
\hline & Bus -1 & 34.98 & 0 & 0 & & & \\
\hline
\end{tabular}




\begin{tabular}{|c|c|c|c|c|c|c|c|}
\hline \multirow{5}{*}{$\begin{array}{c}\text { 2MW@ } \\
\text { Bus } 5\end{array}$} & Bus -2 & 34.98 & 0.0618 & 0 & \multirow{5}{*}{$\underline{0.8022}$} & \multirow{5}{*}{2.4868} & \multirow{5}{*}{$\underline{6.275 \%}$} \\
\hline & Bus -3 & 30.83751 & -0.18281 & 13.43328304 & & & \\
\hline & Bus -4 & 31.72719 & -0.13009 & 10.25243647 & & & \\
\hline & Bus -5 & 33 & -0.10316 & 6 & & & \\
\hline & Bus -6 & 32.39808 & -0.15024 & 7.969361147 & & & \\
\hline \multirow{6}{*}{$\begin{array}{c}\text { 2MW @ } \\
\text { Bus 6` }\end{array}$} & Bus -1 & 34.98 & 0 & $\underline{\mathbf{0}}$ & \multirow{6}{*}{$\underline{0.7581}$} & \multirow{6}{*}{$\underline{2.4342}$} & \multirow{6}{*}{$\underline{6.450 \%}$} \\
\hline & Bus -2 & 34.98 & 0.01981 & $\underline{\mathbf{0}}$ & & & \\
\hline & Bus -3 & 31.25298 & -0.18759 & 11.9253268 & & & \\
\hline & Bus -4 & 32.07369 & -0.13288 & 9.061352155 & & & \\
\hline & Bus -5 & 31.31172 & -0.15355 & $\underline{11.7153577}$ & & & \\
\hline & Bus -6 & 33 & -0.14695 & $\underline{6}$ & & & \\
\hline
\end{tabular}

Table.5 Losses Comparison among Buses

\begin{tabular}{|c|c|c|c|}
\hline Bus Number & $\begin{array}{c}\text { PV } \\
\text { generator } \\
(\mathrm{MW})\end{array}$ & $\begin{array}{c}\text { Real Power } \\
\text { Losses(MVA) }\end{array}$ & $\begin{array}{c}\text { Reactive } \\
\text { power losses } \\
\text { (MVA) }\end{array}$ \\
\hline Bus 3 & 0.5 & 0.9327 & 3.0654 \\
\hline Bus 3 & 1.5 & 0.8526 & 2.6663 \\
\hline Bus 3 & 2.5 & 0.7879 & 2.3561 \\
\hline Bus 3 & 3.5 & 0.738 & 2.1314 \\
\hline Bus 3 & 4.5 & 0.7026 & 1.9897 \\
\hline Bus 3 & 5 & 0.6901 & 1.9491 \\
\hline Bus 4 & 0.5 & 0.9228 & 3.1153 \\
\hline Bus 4 & 1.5 & 0.8499 & 2.8089 \\
\hline Bus 4 & 2.5 & 0.7909 & 2.5633 \\
\hline Bus 4 & 3.5 & 0.7452 & 2.3766 \\
\hline Bus 4 & 4.5 & 0.7127 & 2.243 \\
\hline Bus 4 & 5 & 0.7012 & 2.2037 \\
\hline Bus 5 & 0.5 & 0.8907 & 2.9562 \\
\hline Bus 5 & 1.5 & 0.8261 & 2.6113 \\
\hline Bus 5 & 2.5 & 0.7838 & 2.3933 \\
\hline Bus 5 & 3.5 & 0.763 & 2.2966 \\
\hline Bus 5 & 4.5 & 0.7627 & 2.3172 \\
\hline Bus 5 & 5 & 0.7702 & 2.3707 \\
\hline Bus 6 & 0.5 & 0.8724 & 2.978 \\
\hline Bus 6 & 1.5 & 0.7919 & 2.5972 \\
\hline Bus 6 & 2.5 & 0.7286 & 2.2888 \\
\hline Bus 6 & 3.5 & 0.6819 & 2.05 \\
\hline Bus 6 & 4.5 & 0.6513 & 1.8786 \\
\hline
\end{tabular}


Bus 6

5

0.6419

1.8175 


\begin{tabular}{|c|c|c|c|c|c|c|c|c|c|}
\hline $\begin{array}{c}\text { Voltage } \\
\text { Regulation) }\end{array}$ & \begin{tabular}{|c} 
Voltage \\
Regulation \\
at
\end{tabular} & $|\mathbf{K V}|$ & $\begin{array}{c}\text { Voltage } \\
\text { regulation }\end{array}$ & $\begin{array}{c}\text { Voltage } \\
\text { Regulation } \\
\text { at Bus } \\
\end{array}$ & $|\mathbf{K V}|$ & $\begin{array}{c}\text { Voltage } \\
\text { Regulation }\end{array}$ & $\begin{array}{c}\text { Voltage } \\
\text { Regulation } \\
\text { At bus } \\
\end{array}$ & $|\mathbf{K V}|$ & \\
\hline 0 & \multirow{6}{*}{$\frac{8}{8}$} & 34.98 & 0 & \multirow{6}{*}{7.250} & 34.98 & 0 & \multirow{6}{*}{6.429} & 34.98 & \\
\hline 0 & & 34.98 & 0 & & 34.98 & 0 & & 34.98 & \\
\hline 6 & & 32.16015 & 8.768149402 & & 30.85698 & 13.36170941 & & 31.25562 & 1 \\
\hline 6.833299738 & & 33 & 6 & & 31.65294 & 10.51106153 & & 32.043 & 9 \\
\hline 17.26701478 & & 29.95971 & 16.75680439 & & 33 & 6 & & 31.26981 & 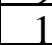 \\
\hline 12.45849115 & & 31.23813 & 11.97853393 & & 32.17896 & 8.704569694 & & 33 & \\
\hline 0 & \multirow{6}{*}{6.988} & 34.98 & 0 & \multirow{6}{*}{7.229} & 34.98 & 0 & \multirow{6}{*}{6.316} & 34.98 & \\
\hline 0 & & 34.98 & 0 & & 34.98 & 0 & & 34.98 & \\
\hline 6 & & 32.17401 & 8.721293989 & & 30.84972 & 13.38838732 & & 31.25595 & 1 \\
\hline 6.493062881 & & 33 & 6 & & 31.70805 & 10.3189884 & & 32.06577 & 9 \\
\hline 17.23459084 & & 29.9574 & 16.76580745 & & 33 & 6 & & 31.29786 & 1 \\
\hline 12.20255737 & & 31.26321 & 11.88870241 & & 32.33241 & 8.188656521 & & 33 & \\
\hline 0 & \multirow{6}{*}{6.904} & 34.98 & 0 & \multirow{6}{*}{7.214} & 34.98 & 0 & \multirow{6}{*}{6.246} & 34.98 & \\
\hline 0 & & 34.98 & 0 & & 34.98 & 0 & & 34.98 & \\
\hline 6 & & 32.18754 & 8.675593102 & & 30.82002 & 13.4976551 & & 31.24803 & 1 \\
\hline 6.193271755 & & 33 & 6 & & 31.74039 & 10.20658536 & & 32.07996 & 2 \\
\hline 17.23848077 & & 29.95047 & 16.79282495 & & 33 & 6 & & 31.32558 & 1 \\
\hline 11.99273104 & & 31.28202 & 11.8214233 & & 32.45682 & 7.773959371 & & 33 & \\
\hline 0 & \multirow{6}{*}{6.839} & 34.98 & 0 & \multirow{6}{*}{7.206} & 34.98 & 0 & \multirow{6}{*}{6.218} & 34.98 & \\
\hline 0 & & 34.98 & 0 & & 34.98 & 0 & & 34.98 & \\
\hline 6 & & 32.2014 & 8.628817381 & & 30.76887 & 13.68633297 & & 31.23252 & 1 \\
\hline 5.936438137 & & 33 & 6 & & 31.75062 & 10.17107697 & & 32.08557 & 9 \\
\hline 17.27739423 & & 29.93925 & 16.8365941 & & 33 & 6 & & 31.35297 & 1 \\
\hline 11.826142 & & 31.29555 & 11.77307956 & & 32.55384 & 7.452761333 & & 33 & \\
\hline 0 & \multirow{6}{*}{6.793} & 34.98 & 0 & \multirow{6}{*}{7.204} & 34.98 & 0 & \multirow{6}{*}{6.230} & 34.98 & \\
\hline 0 & & 34.98 & 0 & & 34.98 & 0 & & 34.98 & \\
\hline 6 & & 32.2146 & 8.584306495 & & 30.69693 & 13.95276335 & & 31.20909 & 1 \\
\hline 5.714570659 & & 33 & 6 & & 31.7394 & 10.21002287 & & 32.08293 & 9 \\
\hline 17.34880271 & & 29.92407 & 16.89586343 & & 33 & 6 & & 31.38036 & 1 \\
\hline 11.70005374 & & 31.30314 & 11.7459782 & & 32.62446 & 7.220165483 & & & \\
\hline 0 & \multirow{6}{*}{6.776} & 3498 & 0 & \multirow{6}{*}{7.205} & 3498 & 0 & \multirow{6}{*}{6.251} & 3498 & \\
\hline 0 & & 34.98 & 0 & & 34.98 & 0 & & 34.98 & \\
\hline 6 & & 32.22153 & 8.560952878 & & 30.65304 & 14.11592455 & & 31.1949 & \\
\hline 5.609245791 & & 33 & 6 & & 31.7262 & 10.25587685 & & 32.07864 & $y$ \\
\hline 17.39689009 & & 29.91483 & 16.93196986 & & 33 & 6 & & 31.39389 & \\
\hline 11.651814 & & 31.30512 & 11.7389 & & 32.6502 & 7.13563776 & & 33 & \\
\hline
\end{tabular}


al losses of the system and the voltage limits when extra 0.5 MW PV generators added to different buses of the system at th

\begin{tabular}{|c|c|c|c|c|c|}
\hline \multirow{2}{*}{$\begin{array}{c}\text { Extra } 0.5 \\
\text { PV generator applied } \\
\text { at different buses } \\
\text { simultaneously }\end{array}$} & \multirow{2}{*}{$\begin{array}{c}\text { Bus } \\
\text { Number }\end{array}$} & \multirow{2}{*}{$\begin{array}{c}\text { Voltage } \\
\text { (KV) }\end{array}$} & \multirow{2}{*}{$\begin{array}{l}\text { Phase } \\
\text { Angle } \\
\text { (rad) }\end{array}$} & \multicolumn{2}{|c|}{ Total System losses } \\
\hline & & & & $\begin{array}{l}\text { Real power } \\
\text { (MVA) }\end{array}$ & $\begin{array}{c}\text { Reactive power } \\
\text { (MVA) }\end{array}$ \\
\hline \multirow{6}{*}{$\begin{array}{c}0.5 \text { MW PV generator } \\
\text { at bus } 3,4,5 \text {, and } 6\end{array}$} & Bus 1 & 34.98 & $\mathbf{0}$ & \multirow{6}{*}{$\underline{0.7345}$} & \multirow{6}{*}{$\underline{2.1695}$} \\
\hline & Bus 2 & $\underline{34.98}$ & 0.04524 & & \\
\hline & Bus 3 & $\underline{\mathbf{3 3}}$ & -0.16991 & & \\
\hline & Bus 4 & $\underline{\mathbf{3 3}}$ & -0.12495 & & \\
\hline & Bus 5 & $\underline{33}$ & -0.14815 & & \\
\hline & Bus 6 & $\underline{33}$ & -0.16008 & & \\
\hline
\end{tabular}

Table.8 2 MW PV generator at bus 6

\begin{tabular}{|c|c|c|c|}
\hline Bus No. & $\begin{array}{c}\text { Voltage } \\
\text { KV }\end{array}$ & $\begin{array}{c}\text { Active } \\
\text { loss } \\
\text { MVA }\end{array}$ & $\begin{array}{c}\text { Reactive } \\
\text { loss } \\
\text { MVA }\end{array}$ \\
\hline 1 & 34.98 & \multirow{6}{*}{$\underline{0.7581}$} & \multirow{6}{*}{$\underline{2.4342}$} \\
\hline 2 & 34.98 & & \\
\hline 3 & 31.25298 & & \\
\hline 4 & 32.07369 & & \\
\hline 5 & 31.31172 & & \\
\hline 6 & $\underline{33}$ & & \\
\hline
\end{tabular}

ble.6 (0.5-5) MW PV Generator applied at each bus and corresponding voltage regulation 